\section{Why scientists cover up fraud}

SIR - John Maddox (Nature 350, 269; 1991) asks why a scientist like David Baltimore should have so vigorously defended what has now proved to be a false position. Philip Weiss raises an even broader issue in his article on scientific fraud (New York Times Magazine 29 October 1989), namely why "no one who was equipped to wanted to get to the truth of the matter ...". Although the statement is false, as Weiss reveals, it brings out the essence of a dilemma: why do scientists tend to cover up and deny scientific fraud?

As a scientist saddled with the aftermath of a parallel scandal, the Darsee affair, I wish to suggest a possible answer: researchers routinely accept a certain level of dishonesty and therefore defend larger transgressions that involve the same vice. The particular corruption that I speak of is unearned authorship.

Earned authorship in scientific papers means doing the experiments, analysing the data, working out the theory, writing the paper, reading the literature - these activities enable an author to lecture on the paper in front of a critical audience. Merely encompassing the work under the umbrella of one's interest and ideas does not.

Why do scientists expose themselves in this way? For one thing, putting one's name where it does not belong is rewarded by granting agencies and tenure committeees. Close colleagues easily spot perfunctory authors, but more distant evaluators may merely count articles. Separate groups that are funded jointly may also work independently on the project, and a common temptation is to add each other's names to what should be autonomous articles.

But these motives would not explain why senior scientists with numerous grants and important positions would sign their name to an article they have barely read, much less worked on. Perhaps conceit drives unearned authorship, the need to stake a claim to a discovery one is minimally involved with. Intellectual participation is an excuse for this tactic, but that often means having done what any informed colleague would do casually and without credit, except perhaps in the acknowledgements. Because of administrative or monetary relationships between senior and junior scientists, marginal contributions may be elevated to authorship.

At Emory University, during the investigation of the Darsee affair, the argument was made that junior scientists cultivate senior co-authorships in order to get their work published. The review system should not work that way, though frequently it may. Regardless, this argument puts the blame on the privates and lets off the generals. Established scientists, under pressure to obtain extramural funds, are burdened with the baggage of success: leadership in national societies, membership of editorial boards and grant review panels, travel and lectures, committees and administration. These activities drain the time and the energy of every established investigator, and they make bench research nearly impossible. Yet the pressures to present oneself as being at the vanguard of research are greater then ever.

By accepting or insisting upon unearned authorship, much of the scientific community has forfeited the right to bear witness. Thus, when investigations reveal unbecoming conduct that involves the same crime, scientists close their ranks, because many are guilty of far less spectacular but similar infractions.

LOUIS J. DeFELICE

California Institute of Technology,

Division of Biology 156-29,

Pasadena, California 91125, USA

\section{Perspectives for India}

SIR - Few would disagree that the developing countries stand to suffer the most from environmental problems such as loss of biological diversity, degradation of ecosystems, environmental pollution and contamination, and other aspects of global change. I suggest that Indian universities have a particular contribution to make by stimulating collaborative ecological training and research to address the regional environmental problems of south Asia.

It is apparent that the traditional university departments designed for compartmentalized teaching of botany or zoology do not provide the kind of training needed for the new generation of ecologists who need to understand complex ecosystems in order to predict, plan and manage the environment and resources of tomorrow. Special emphasis needs to be placed on five areas of research: ecosystems analysis and modelling; conservation and evolutionary ecology; environmental biotechnology; ecology of global change; and ecological economics.

Development of this expertise will require a new university infrastructure, which could take the form of interdisciplinary centres or of wholly new departments such as the one at Jawaharlal Nehru University, New Delhi, but with greater interaction among the disciplines.

Any reorganization within a higher education system will encounter resistance from the inertia of the system and from worries as to whether environmental concerns will indeed result in an increased demand for ecologists. Advanced teaching programmes will have to be integrated with real life, long-term research programmes so that teaching and research fit snugly with each other. The new approach would further require a coordinated network of sites for monitoring long-term trends, along with year-to-year variability, in selected natural and man-modified ecosystems for facilitating comparative experiments and for studying ecological phenomena that occur on timescales of decades orlonger.

I believe that India has a special responsibility for the whole of south Asia because of the country's relatively welldeveloped scientific infrastructure. Biosphere reserves that have been and are being established in India represent all the ecological conditions of south Asia, from arid desert and wet tropics to alpine regions. Finally, India already has bilateral agreements and exchange programmes with several developed and developing countries, which could be built on in the future.

Ecosystems Analysis Laboratory,

Banaras Hindu University,

Varanasi 221005, India

\section{Baer facts}

SIR - On 28 February 1992, 200 years will have passed since the birth of Karl Ernst von Baer, the distinguished biologist, and at the end of February 1992 the Estonian Academy of Sciences will hold an international conference dedicated to Baer in Tartu, where he studied at the university (1810-14) and spent the last years of his life (1867-76).

In 1976, the Baer Museum was opened in Tartu, where materials connected with Baer are displayed, his letters are studied and investigations in the field of evolutionary theory and the philosophy of biology are carried out. Numerous works by and about Baer, including manuscripts, letters, photographs, pieces of art and other materials, are preserved there. Material on Baer can also be found in Leningrad, Tallinn and Giessen. Only part of this material has been studied and published, including nearly 800 letters by Baer.

One of the main aims of our activities is to publish almost the whole of Baer's collection of letters, and I should be very grateful to anybody who can provide me with information about them. The Baer Museum would be glad to have copies of the letters, or any information on where they are preserved.

Karl Ernst von Baer Museum,

VeLLo KAAVERE

Veski 4,

202400 Tartu, Estonia

NATURE · VOL $353 \cdot 12$ SEPTEMBER 1991 